\title{
Lágrimas na chuva: reflexão epistemológica sobre desumanização e desperdício da tecnologia educacional
}

\author{
Tears in the rain: epistemological reflection on dehumanization and \\ waste on educational technology
}

http://dx.doi.org/10.5007/2178-4582.2014v48n1p4

\author{
Filipe de Menezes Jesuino, Marcos Antonio Martins Lima, Andréa Moura da \\ Costa Souza e Gabrielle Silva Marinho \\ Universidade Federal do Ceará, Fortaleza/CE, Brasil
}

\begin{abstract}
Este ensaio apresenta um trabalho de pesquisa que focaliza a descrição, o estabelecimento e a compreensão das relações entre o filme Blade Runner, dirigido por Ridley Scott e lançado em 1982, e a circunscrição epistemológica da técnica educacional com base na filosofia da ciência de Bachelard e de uma aproximação teórica do problema da tecnologia no âmbito da educação de acordo com autores como Martin Heidegger, Álvaro Vieira Pinto e Pedro Demo. A investigação seguiu o método bachelardiano de partir do objeto poético para a crítica fundamentada no espírito científico. Assim, dois aspectos principais foram abordados: (i) articular o problema da tecnologia e as atividades relacionadas de forma poética; (ii) a concepção de uma reflexão crítica sobre o devir psíquico e a evolução tecnológica. As análises permitiram identificar a importância de uma vigilância epistemológica da técnica educacional que pode preservar seu valor cientificamente confiável.
\end{abstract}

Palavras-chave: Tecnologia - Epistemologia Educação - Blade Runner
This paper presents a research which focuses on the description, establishment and understanding of the relations between the movie Blade Runner, directed by Ridley Scott and released in 1982, and the epistemological circumscription of the educational techniques based on Bachelard's philosophy of science and on the theoretical approach of the problem of technology in education according to authors such as Martin Heidegger, Alvaro Vieira Pinto and Pedro Demo. The investigation followed the bachelardian method of going from the poetical object to the criticism based on the scientific spirit. Thus, two main issues were addressed: (i) articulating the problem of technology and its related activities in a poetic form; (ii) the design of a critical reflection about the psychic becoming (devir) and technological development. The analysis allowed us to identify the importance of the epistemological vigilance over the educational technic, which can preserve its reliable scientific value.

Keywords: Technology - Epistemology - Education - Blade Runner

\section{Introdução}

Nossa reflexão enfoca a importância da vigilância epistemológica como ferramenta útil para que a técnica não degenere em instrumentalidade ingênua, tendo-se em vista o vertiginoso avanço tecnológico no campo da educação. Compreendemos que algumas das críticas dirigidas às novas tecnologias, e mesmo a desilusão diante de alguns recursos de vanguarda, que não logram o resultado esperado, dirigem-se mais precisamente à apropriação epistemologicamente limitada. Visto por esse ângulo, o alvo da crítica se delineia como 
uma carência reflexiva que despreza alguns aspectos fundamentais do avanço científico da técnica. O resultado fundamental é uma alienação do processo humano envolvido na técnica, o que implica um misto de desperdício e desumanização do trabalho.

Podemos observar que parte da produção recente, ao menos no Brasil, assume uma posição que muito rapidamente admite as benesses das novas tecnologias sem que, no mais das vezes, sequer seja feito um alerta quanto aos riscos envolvidos. Derivam, assim, textos que não deixam claras suas posições. Não se exprimem quanto à criticidade ético-epistemológica que recai (ou não) sobre os usos da tecnologia que propõem ou desenvolvem em suas pesquisas. Ao menos na publicação que nos é acessível, é inopinada a admissão de certos posicionamentos. Destacamos alguns exemplos da produção recente: "[...] a tecnologia educacional passou a corresponder a uma maneira sistemática de organizar o processo de ensino e aprendizagem em termos de objetivos e da combinação de recursos humanos e materiais para resolver os problemas da educação" (NESPOLI, 2013, p.874); "[...] a utilização das tecnologias educacionais proporciona a capacitação do aluno [...]" (FROTA, 2013, p.30); "[...] a aplicabilidade da informática influencia todas as áreas do conhecimento, através da difusão de informações, criação de programas de ensino e geração de controvérsias, possibilitando, assim, novas formas de aprendizagem" (BARRA, 2012, p.467).

A esse respeito, o texto de Fonseca (2013, p.2) e seus colaboradores merece destaque ao asseverar que "A disseminação do uso de tecnologia educacional é estimulada por suas inúmeras vantagens", que são listadas no documento e às quais se segue importante consideração: "Embora essas vantagens sejam reconhecidas, as tecnologias educacionais precisam ser avaliadas para garantir a qualidade do programa" (Ibid.). Sua argumentação consequente aproveita a proposição para defender o valor central da figura do professor. Nós a aduzimos para indicar a importância da reflexão epistemológica como parte da pretendida avaliação das tecnologias, o que defendemos ser indispensável, com fundamentação teórico-filosófica, para evitar que a tecnologia resulte em " [...] limitar excessivamente as possibilidades de expressão do sujeito, forçando-o ao encarceramento na técnica e na imagem parcelar" (JESUINO; JESUINO; RIOS, 2011, p.126).

Esse risco produzido pela técnica não é apenas um devaneio de mentes desocupadas, mas um problema que tem estado em foco na discussão educacional, malgrado não ser tão recorrente na produção periódica. Pedro Demo (2009; 2010), por sua vez, destaca que o avanço tecnológico implica vantagens e desvantagens e que o fiel da balança, no mais das vezes, está vinculado ao uso que se faz dela, e não à tecnologia em si mesma, como se tratasse de uma entidade autônoma. Destaca que é necessário um comprometimento lato do homem com a técnica que ele produz e que se impõe, daí por diante, como construto cultural inescapável. O homem, ao seu ver, precisa se implicar com o que faz, incluindo a técnica em um sistema de compreensão, e não alienar-se 
de si em nome dela, trocando o todo pela parte e se desresponsabilizando por seus usos. A técnica não atua sem o homem, mas atua sem reflexão.

Esse é o ponto de partida da nossa proposta que não pretende mais do que desenvolver e demonstrar um aspecto da reflexão dita necessária, que é a reflexão epistemológica. Na persecução dessa meta, partimos da circunscrição epistemológica da técnica com supedâneo na filosofia da ciência de Bachelard $(1977 ; 1996 ; 2006)$ e de uma aproximação teórica do problema da tecnologia no âmbito da educação, com ênfase nas ideias de Pedro Demo $(2009 ; 2010)$, Heidegger (2008) e Álvaro Vieira Pinto (2003; 2005). Tomamos como eixo metodológico a trilha metafórica apresentada pelo filme Blade Runner (1982), de Ridley $\operatorname{Scott}^{1}$, que articula o problema da tecnologia de forma poética. Com isso, de acordo com Bachelard (2009, p.8), acessamos o devir psíquico mais imediato para, em seguida, submetê-lo à reflexão crítica, desfazendo a ingenuidade da aproximação primeira.

Iniciamos o argumento com as palavras finais do antagonista, Roy Batty:

\begin{abstract}
Vi coisas que vocês humanos não acreditariam: naves atacando nas bordas de Orion; contemplei raios $\mathrm{C}$ brilhando nos portões escuros de Tanhauser. Todos esses momentos estarão perdidos no tempo - como lágrimas na chuva. Hora de morrer (BLADE, 1982).
\end{abstract}

O discurso parte de um androide ou, na linguagem do filme, de um replicante, uma máquina produzida pelo homem à sua semelhança, simulacro que pretende realizar trabalhos insalubres. Em sua última geração, chamada de Nexus 6, são capazes de produzir emoções, tornando-se praticamente indistinguíveis de um humano real. Há efeitos colaterais, porém, nesses últimos: eles têm curto prazo de funcionamento, quatro anos apenas e, além disso, podem se rebelar contra seus criadores. Aí, entram em ação caçadores responsáveis por desativá-los prematuramente, um assassinato chancelado com o nome de "aposentadoria".

Batty liderava um grupo desses androides em busca de seu criador, o Dr. Tyrell, para demandar extensão de seu prazo de "vida". O cientista, todavia, mostrou-se incapaz de fazê-lo, pois a tecnologia que produziu gerou problemas que ultrapassavam suas capacidades de resolução. Demandavam pesquisa e, assim, o cientista não sabia quando, ou mesmo se, poderia reverter o quadro. Batty, fadado à extinção, o matou.

O caçador Deckard, protagonista e responsável por dar cabo ao grupo de Roy, foi derrotado por ele. O replicante, ao pressentir o próprio fim, porém, poupou a vida do humano. Em seu discurso final representou em palavras a situação da própria tecnologia. Revelou o que ela poderia dizer ao ser humano, o

\footnotetext{
1 Inspirado na obra Do Androids Dream of Electric Sheep? de Phillip K. Dick (1984), publicada originalmente em 1968.
} 
que era capaz de ver. Podemos traduzir seu discurso na forma de um problema: "Vocês passaram a combater sua própria criação, capaz de ajudá-los a enxergar e viver coisas inacessíveis ao homem natural. Embora sejam nosso criadores, não souberam nos dar respostas satisfatórias aos problemas que trouxemos e, por isso, condenaram-nos. Desperdiçaram nosso potencial, tornaram-nos o inimigo. Nós, que não somos mais que um espelho de sua ciência”.

Eis o argumento para uma reflexão bastante atual. O filme aborda uma reflexão até hoje pertinente e que já se expunha no discurso de Phillip K. Dick (1995), de 1972, sobre o avanço das máquinas e a ideia ficcional dos androides Ele escreveu que "[...] os construtos não imitam humanos, eles já o são, sob muitas e profundas maneiras. Eles não estão tentando nos enganar, por qualquer motivo; eles apenas seguem as linhas que seguimos". (DICK, 1995, p.185, tradução nossa).

Essa ideia, haurida de um ensaio sobre literatura, não deixa a dever à reflexão de Vieira Pinto (2005) ao argumentar que não se pode imputar finalidades nocivas e desumanas ao emprego da técnica por ele mesmo. A técnica reflete o progresso da humanização, seu uso antissocial e dominador deriva dos propósitos humanos, é seu espelho. Pertence à essência da técnica, portanto, uma função humanizadora.

O mesmo pode ser ponderado no campo da educação. Podem, por si próprias, as novas tecnologias - como os Ambientes Virtuais de Aprendizagem, os recursos da Educação Semi-Presencial, as técnicas de didática ou os dispositivos eletrônicos - garantir bons resultados educacionais? Ou serão elas as vilãs que devem ser "aposentadas" em razão de seus resultados por vezes lamentáveis? Cuidaremos de demonstrar que até a proposição de tais questionamentos já sinalizam a perda, como lágrimas na chuva, da função cientificamente construtiva e humanizadora da técnica.

\section{A importância da vigilância epistemológica da técnica}

Uma das funções fundamentais da epistemologia na prática científica, segundo De Bruyne, Herman e Schoutheete (1991, p. 35) é estabelecer um questionamento dos princípios. Este papel faz recordar, com Bachelard (1996, p.18), que na ciência "[...] nada é evidente. Nada é gratuito. Tudo é construído". O questionamento é imprescindível, pois os produtos científicos sejam conceitos, técnicas ou processos -, sem esse questionamento recorrente, podem declinar em seu uso, perder seu valor problemático e se perpetuar como respostas reduzidas a fatos brutos. Tornam-se evidências, existentes por si próprias, perdendo sua história e sua operacionalidade.

Pelo enfoque bachelardiano, o espírito científico não admite tal dado concreto, apenas o "fato de cultura", construído no diálogo da empiria com a racionalidade (BACHELARD, 2006). É necessário fazer uma psicanálise desses fatos brutos e reconstituir a lógica subjacente (Id.,1996). O pensamento de 
Bachelard, pois, ao mesmo tempo propicia e exige o questionamento investigativo contínuo dos princípios, teorias e técnicas. Ao enfocarmos a avaliação educacional não é diferente.

Bachelard assume, no seu intuito crítico, uma posição dialética que "[...] não pode aceitar nem a solução realista nem a idealista" (LIMA, 2004, p.101) da ciência. Ambas se encontram em diálogo constante no espírito científico. Assim, consoante Barbosa (2003, p.35), "experiência e razão reclamam um racionalismo aplicado, isto é, uma constante fusão do sistema de razão teórica e experiências técnicas".

O racionalismo é aplicado porque se dirige continuamente à experiência, ao mesmo tempo em que é informado por ela. Garante, assim, o movimento e a reformulação da ciência. A técnica produzida pela ciência é, pois, um dos fatores de articulação do pensamento. Isso corresponde, consoante Bachelard, ao materialismo técnico, uma realidade modificada ou (re)criada pela ação indutora da razão. O ciclo resultante atua como motor científico:

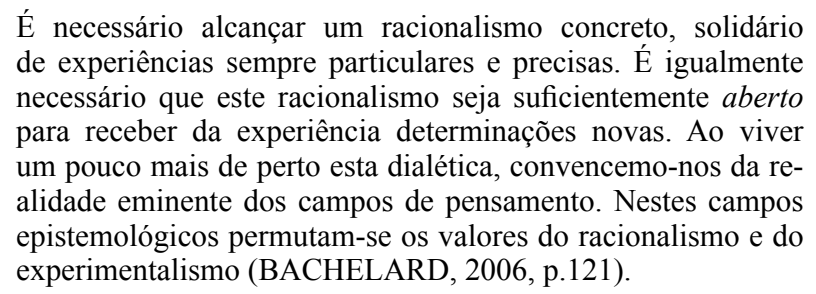

O avanço da racionalidade implica produção de técnica e de experiência renovadas. Estas se apresentam ao pensamento como novas "realidades", nova experiência que mobiliza o instinto de formação e renovação (BACHELARD, 1996). É, pois, em razão da sua solidariedade com a experiência que a razão se vê impulsionada ao corte com posições científicas prévias. Assim como avança o pensamento, portanto, é possível asseverar com Lima que “[...] o novo espírito científico é uma verdadeira fábrica de tecnologia [...] e de técnicas" (2004, p.114).

A realidade sobre a qual se debruça a ciência contemporânea, destarte, não é um mundo de fenômenos naturais, disponíveis imediatamente ao observador despreparado. No mundo do cientista, "o fenômeno natural não mais se apresenta como aquele que pode ser observado pelos sentidos, mas esse fenômeno é produto de aparelhos, é produto de técnicas altamente elaboradas" (BARBOSA, 2003, p.35). A fenomenotécnica é prolongamento da fenomenologia (BACHELARD, 1996). Na metáfora que assumimos, os replicantes são simulacros do homem, mas indistintos dele à primeira vista. Somente diante do conhecimento científico mais sofisticado se é capaz de distinguir entre os dois.

Bachelard afirma a esse respeito que para garantir a cientificidade da técnica "[...] é preciso haver outros conceitos além dos conceitos "visuais" e, 
por isso, somente por "uma desmaterialização da experiência comum se pode atingir um realismo da técnica científica" (1977, p.160). Somente ao "[...] olho treinado", o fato bruto deixa de sê-lo. A fenomenotecnia é compreendida como algo construído.

Se não há essa construção incorre o obstáculo. Compreendemos esse processo com mais apuro ao recordar, com Vieira Pinto (CORONEL; SILVA, 2010), que é possível distinguir duas atitudes principais do homem em relação à tecnologia. Por um lado, o homem primitivo se deslumbra com os fenômenos da natureza enquanto, pelo outro, o civilizado se maravilha com objetos tecnológicos. Esse encantamento pode corresponder tanto a uma atenção meticulosa - interesse apaixonado, conforme definiu Bachelard (2006) - quanto ao obstáculo da experiência primeira (Id.,1996), abordagem ingênua da (fenomeno)técnica.

Isso ocorre quando o instinto formativo cede lugar ao conservativo. Debilita-se, assim, o pensamento que acaba por ser levado "[...] por um lado, do racionalismo ao idealismo ingênuo e, por outro, do materialismo técnico ao realismo ingênuo" (BACHELARD, 2006, p.122). A técnica resta, destarte, esvaziada de sua racionalidade intrínseca, ao menos aos olhos do observador despreparado, e perde, portanto, seu valor de renovação da ciência. Torna-se mais prisão que motor, método convertido em hábito. Enfim, transforma-se em obstáculo realista. Requer, pois, corte epistemológico para avançar.

Heidegger (2008) ofereceu uma perspectiva sobre a técnica que ratifica, por outro ângulo, a perspectiva bachelardiana. Para ele, a produção relativa à técnica não se confirma no sentido do manuseio ou da feitura de algo, mas no descobrimento, que é onde acontece a $\dot{\alpha} \lambda \dot{\eta} \theta \varepsilon ı \alpha$, ou seja, a verdade. Critelli (2002) destacou que para o filósofo, trata-se da forma privilegiada do ocidente de fazer avançar seu pensamento, de expressar no fenômeno o seu modo de ser. No entanto, se a atenção se volta apenas para o ente da técnica e se desvia do permanente devir do descobrimento propiciado por ela, o ser é posto de lado. Neste último caso, a técnica acabaria por substituir-nos "[...] naquilo que mais nos caracteriza em nossa humanidade, [...] que é sermos "pastores do ser', cuidadores do ser" (CRITELLI, 2002, p.89). O "ser criativo" que revela a verdade é deposto pela sobrevalorização do ente da técnica.

Diante desse risco, Bachelard (1977) propõe a vigilância intelectual de si como tarefa epistemológica crucial. Trata-se de uma atitude reflexiva, (auto) avaliativa, que extrai do diálogo quotidiano entre o empirismo e o racionalismo o valor do erro e o assume como impulso para a inovação. Isso só é possível quando "o conhecimento é tomado no par do racionalismo aplicado: é preciso sempre que um fato julgue um método; é preciso sempre que um método tenha a sanção de um fato" (BACHELARD, 1977, p.78).

A vigilância se desdobra em quatro níveis exponenciais. No primeiro, funda a expectativa pelo fato definido, caracterizado, uma racionalidade aberta para a atividade empirista. O segundo nível (vigilância $\left.{ }^{2}\right)$ é a vinculação da 
atitude expectante à aplicação rigorosa de um método. Oportuniza, dessa maneira, o esclarecimento das relações entre teoria e experiência e de como ela é operada. O método censura as formas possíveis de estabelecer essa conexão. Já a vigilância elevada ao cubo atua "[...] quando se vigia não apenas a aplicação do método, mas o próprio método [...], exigirá que se ponha o método à prova" (BACHELARD, 1977, p.94-95). Dessa maneira, compreende o método atual como um momento - finito - dos seus progressos históricos e possíveis.

Além daí, mesmo esse terceiro nível pode ser posto em xeque pela poética, que constitui outra epistemologia. Nessa extrema vigilância ${ }^{4}$, a fixidez superficial do homo faber, homem da razão aplicada, cede lugar ao "[...] homem das profundezas e o homem de um devir" (BACHELARD, 1994, p.83), pois a imaginação "[...] é um fator de imprudência que nos afasta das pesadas estabilidades" (Id., 2009, p.8). A divagação poética exige que nos libertemos “[...] dos livros e dos mestres para reencontrarmos a primitividade poética" (1989, p.44). Assim, com o abandono da dureza e do rigor científicos, readquire-se o contato com o devaneio que é capaz de fornecer novos objetos, tarefa do amanhecer de toda investigação científica.

Ao importar a reflexão de Bachelard, haurida dos problemas das ciências da natureza, é necessário lembrar, com Ferreira Filho (2005), que também as ciências sociais só operam mediante corte epistemológico evidente. A respeito delas, tanto a linguagem na qual se expressam quando o campo de relações a que se referem estão, em princípio, acessíveis $e$ inacessíveis à opinião comum, pois o espírito ingênuo compreende os fenômenos como fenômenos quotidianos ordinários. Somente a vigilância do espírito instruído pode desvelar a realidade social fenomenotécnica. Esta, nas ciências sociais, depende da formulação conceitual e da ação obstinada do espírito científico que operam contra as noções primeiras e com o realismo ingênuo.

Pode-se argumentar, com Bachelard (1996, p.168) que, sobretudo no campo das ciências humanas, entre a abordagem comum e a científica, "[...] a designação é a mesma, mas a explicação é diferente". É necessário, para que se chegue ao trabalho de uma ciência social, "[...] mudar de cultura experimental, eliminar os obstáculos já acumulados pela vida quotidiana".

De Bruyne, Herman e Schoutheete (1991) afiançam, por sua vez, que as ciências sociais não podem dispor de um corte propriamente dito, já que são, elas mesmas, práticas sociais. Para os autores, o que se opera nesse campo é uma ruptura "[...] a ser sempre recomeçada, continuada, reformulada" (p.34). Delas não se pode esperar corte absoluto, mas vigilância perene, caso contrário, "[...] correm também o risco de perderem identidade, de perecerem". (FERREIRA FILHO, 2005, p.335).

Esse ponto de vista se integra à perspectiva mais geral de Bachelard, para quem é necessário "[...] colocar a cultura cientifica em estado de mobilização permanente, substituir o saber fechado e estático por um conhecimento aberto 
e dinâmico" (1996, p.169). As ciências sociais dependem de uma crítica contínua que se oponha à regressão ao concreto psicológico da razão e das coisas.

Assim, também no âmbito das ciências sociais se evidencia a necessidade da permanente vigilância da técnica para que elas não sejam posicionadas em oposição ao homem pelo conservadorismo intelectual. Ao reconhecer a técnica como autônoma e, por isso, estranha, o sujeito da ciência se aliena de si. Opõe-se à técnica com sua razão, perde a vivacidade dialética. A tal intelectual racionalista-ingênuo restam duas possibilidades pobres: aposentar a técnica ou ser consumido por ela.

\section{Tecnologia educacional: autonomia, uso e abuso}

No nosso trabalho, a consideração da técnica se especifica em sua operacionalidade educacional. Para fins práticos, é suficientemente abrangente e precisa a posição de Álvaro Vieira Pinto (2003) que compreende como erro lógico e filosófico relacionar educação apenas à infância e à adolescência. Ele a reconhece como formação (Bildung) integral do homem pela sociedade. É, pois, processo histórico, existencial e sociocultural. Além disso, depende de fatores econômicos e políticos e requer planejamento, reflexão e precisão em seus postulados de base.

O filósofo destaca que a educação se vincula a uma inércia, pois pretende formar os indivíduos de acordo com o estado atual da sociedade (PINTO, 2003). Ao mesmo tempo, porém, trata-se de progresso, pois implica necessária ruptura da condição vigente que propicia um processo criativo, perspectiva que se aproxima à função de vigilância do racionalismo aplicado (BACHELARD, 1977).

Para delimitarmos a noção de tecnologia no âmbito educacional, urge pensar o que significa, mais precisamente, técnica e tecnologia. Na concepção de Vieira Pinto, de acordo com Coronel e Silva (2010), é imperioso distinguir as duas instâncias, pois "[...] a técnica é imanente à espécie humana, a única dentre todas as espécies vivas, que tem por natureza própria a faculdade de produzir e inventar meios artificiais de resolver problemas". A tecnologia, por sua vez, deve ser reconhecida como filosofia ou ciência da técnica e "[...] surge como exigência social numa etapa ulterior da história evolutiva da espécie humana". (CORONEL; SILVA, 2010, p.182).

Vieira Pinto condenava as posturas maniqueístas diante da tecnologia. Ela não é boa ou má por si mesma, mas acompanha amplamente a atitude ética e moral do homem. As posições que partem de petições de princípio quanto à natureza moralmente polar da tecnologia são restritivas. Em sua obra máxima a respeito do tema (2005), o filósofo asseverou que a técnica não determina o destino do homem, antes o homem decide o destino da técnica, é sua responsabilidade fazê-lo. 
A palavra técnica, derivada do latim, technicus e do grego $\tau \dot{\chi} \chi v \eta$ (téchne), significa o "[...] conjunto de regras ou procedimentos próprios de um ofício com fins de concretizar determinados resultados" (ALBUQUERQUE; MA-

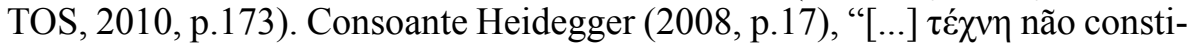
tui apenas a palavra do fazer na habilidade artesanal [...] pertence à pro-dução,

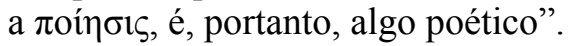

De forma mais atual, refere-se a procedimentos ou instrumentos produzidos pela ação cultural humana que são utilizados em certas atividades para a obtenção de certas finalidades prescritas. No sentido que lhe é conferido por Heidegger (Ibid.,p.20), a técnica moderna tem o sentido de exploração, um movimento no qual "[...] a energia escondida na natureza é extraída, o extraído se vê transformado, o transformado, estocado, o estocado, distribuído, o distribuído, reprocessado". Em seu movimento, conforme a ideia de Heidegger, a técnica favorece articulação extrativa, comunicativa e transformadora. Não apenas revelando, mas produzindo a realidade educacional.

Albuquerque e Matos (2010) assinalam que hodiernamente há uma tendência a se admitir a subordinação do existir diário, nos seus diversos desdobramentos, aos processos produtivos, instrumentos e técnicas. Constitui-se, assim, uma tecnocracia que atinge, inclusive, a prática educacional, em geral, e a avaliação, especificamente. As autoras, no entanto, defendem que a escolha dos instrumentos deveria partir da reflexão a respeito dos objetivos e do contexto educacional em que serão postos em prática. A reflexão, idealmente, circunscreve a técnica. Esta serve a um planejamento, não o conduz, o que está em consonância com os princípios de Bachelard e com os conceitos de educação de Vieira Pinto.

Tecnologia, por sua vez, “[...] consiste no saber (conhecimentos científicos aplicados à produção) historicamente acumulado através da apropriação sistemática dos conhecimentos intrínsecos à própria prática do trabalho" (SIMÕES, 2002, p.29). Demarca-se como ciência da técnica e, por isso, conforme Simões, resguarda conformidade com a epistemologia bachelardiana: está a serviço de uma construção reflexiva e transformadora da realidade.

Conforme Vieira Pinto (BANDEIRA, 2011), a tecnologia não é um dado circunstancial, mas um dos fatores que definem o homem. Articula-se, pois, inextrincavelmente, com seus outros fundamentos, inclusive com a produção social. A redução da tecnologia à sua mera aplicabilidade é fenômeno de relevo sociopolítico da era (pós)industrial. Algumas classes (proletariado) são levadas, por outras a essa perspectiva restrita por outras que tentam resguardar acesso à sua (re)criação e entendimento.

Duas coisas podem ser depreendidas daí. Em primeiro lugar, o risco de se perder o valor racional (aplicado) da técnica não apenas é problema epistemológico geral, mas também sociopolítico. Adicionalmente, a admissão da técnica sob a perspectiva de um realismo ou pragmatismo ingênuos não $f a z$ dela boa ou má, mas retrata, além da indigência científica, uma 
alienação da responsabilidade ética do homem à própria técnica, o que é uma contradição nos termos. Dessa maneira, apenas se consegue alienar, como já referimos, a responsabilidade humana à técnica, como se ela fosse autônoma, o que não é. E não pode sê-lo, mesmo que a humanidade alegue asylum ignorantiae.

Essa alienação da responsabilidade ética não isenta o sujeito humano, apenas retrata sua insuficiência intelectual e moral. É irresponsabilidade. Esse é o subtexto que depreendemos do discurso de Roy Batty. Ele, como técnica, não mata o caçador Deckard, dá-lhe um golpe moral bem mais severo. Expõe o homem que, em sua incapacidade de acompanhar a própria produção, permite que morram com ela, universos de conhecimento inexplorados.

A visão ficcional do androide de Blade Runner encontra consonância com as reflexões de Pedro Demo, em seu texto intitulado Tecnofilia e Tecnofobia (2009). Ele argumentou, ali, que a profusão das novas tecnologias na educação - e além dela - é característica de nosso tempo com a qual temos que lidar necessariamente. Por um lado, atende a interesses neoliberais pouco zelosos com a educação e, por vezes, contrários a ela. Pelo outro, todavia, pode se inserir de forma a contribuir para o aprimoramento da aprendizagem. Daí, Demo (2009) considera importante encontrar uma posição equilibrada entre a admissão e o repúdio extremos dessas tecnologias.

Em outro texto, o autor (DEMO, 2010) destacou que muito do que é tratado como "nova tecnologia" sequer merece tal designação, pois não passa de renovação, ou seja, de novas formas das técnicas antigas. Ainda assim, quando reduzidas à mera aplicabilidade, nem seu valor inicial se sustenta, pois perde o relevo reflexivo e mobilizador de novas ideias. Converte-se em prática a serviço de formas antiquadas de racionalidade e perde, assim, seu interesse de renovação para o pensamento e as atitudes. Ao invés de garantir avanço, atrasa o homem.

No célere progresso tecnológico das duas últimas décadas, destacaram-se os campos da informática e das relações virtuais. Emergiram recursos que, potencialmente, favorecem acesso facilitado à educação, redução de custos e diminuição da recorrência às aulas tradicionais, à presença física e à autoridade centrada no professor. Nesse sentido, as duas motivações que mais se destacam quanto à admissão dessas tecnologias são a oportunidade de ampliação do mercado educacional e do acesso à educação e a melhoria das própria aprendizagem em decorrência de sua reconfiguração. Para o autor, esse último fator é o decisivo, pois, "[...] se não ocorrer aprendizagem de qualidade, nada se inovou ou acrescentou" (DEMO, 2009, p. 6). A preocupação mais importante, pois, é o desafio pedagógico de se absorver as novas tecnologias como melhoria da educação, e não, simplesmente, como ampliação ou diversificação dela.

Demo destaca que nesse sentido é mister a avaliação contínua. Em suas palavras: "[...] torna-se importante saber avaliar a credibilidade das fontes vir- 
tuais, acessando-as como material de pesquisa e interpretação crítica e autocrítica, fazendo isto parte eminente do processo de alfabetização" (DEMO, 2010, p.2). Esse cuidado se vincula mais uma vez à vigilância epistemológica, mas vai adiante, vincula-se ao questionamento sobre as reais mudanças implementadas pelas novas tecnologias sobre as pessoas e as sociedades.

\section{O potencial perdido entre homens e simulacros}

O filme que tomamos como metáfora foi sobejamente discutido no decorrer das décadas desde sua publicação. As interlocuções são as mais diversas e, ainda assim, continua propiciando reflexões iluminadoras. Antes de proferir suas últimas palavras, o replicante Roy Batty realizou algo inesperado: salvou a vida de seu algoz. Adiante, Deckard afiançou: "Talvez nos seus últimos momentos ele tenha amado a vida mais do que em qualquer outro. Não apenas a sua vida. Qualquer vida. Minha vida" (BLADE, 1982). Esse critério, a valorização do outro, foi a faceta chocante do androide assassino. Toda simplicidade maniqueísta caiu, ali, por terra. Como decidir entre bem e mal?

Em texto sobre o filme, Metin Bosnak escreveu que "[...] no filme, nem o capitalismo nem o avanço na ciência e na tecnologia parece ter ajudado a humanidade a desenvolver ética e felicidade. Eles não tem um telos ou um ethos" (BOSNAK, 2002, p.88). A humanidade retratada carecia, pois, de um objetivo comum ( $\tau \varepsilon ́ \lambda o \varsigma)$ que os unisse e, ao mesmo tempo, de um caráter ( $\tilde{\eta} \theta$ o $)$ ) próprio, que apresentasse sua configuração coerente. Dispunha, no entanto, de técnica avançadíssima que avançou sem o desenvolvimento moral ou o compromisso com qualquer ideal democrático ou formativo, tão caro aos pensadores da nossa educação contemporânea, como Gramsci, Giroux, Paulo Freire e Dermeval Saviani.

Vale (1999), em outro estudo sobre a película, argumenta que ali se satura a substituição do homem pela máquina, perigo real argumentado também por Vieira Pinto. Nem mesmo isso destitui a responsabilidade moral, apenas a preserva sob uma máscara. Esta acaba por garantir ao homem uma alternativa de escape: a tecnologia é a culpada, e merece ser destruída. Ele se viu em oposição à máquina, incapaz de se reconhecer nela ou de se diferenciar adequadamente.

Demo (2009) assinala que há riscos inerentes ao avanço tecnológico, sobretudo quanto é vertiginoso, ele une sempre vantagens e desvantagens. Predispõem modismos, crenças em resultados utópicos, tiram a atenção dos problemas reais e isso, muitas vezes, leva a utilização dos novos recursos segundo posturas antiquadas, pois a nova tecnologia se insere, em geral, na continuidade das atitudes. Essa é a atuação da máscara, é alienar à técnica um aspecto do homem - a responsabilidade que caberia ao homem integral.

$\mathrm{O}$ autor, por outro lado, indica, ao tratar das novas alfabetizações, tornadas possíveis pelas novas tecnologias, que 
[...] emergem como processo rápido e contínuo de mudança em todos os modos de comunicação; [...] isto implica mudança de mentalidade, em especial a percepção de que é preciso, de modo permanente, mudar e mudar-se face a novas configurações dos tempos e tecnologias (DEMO, 2010, p.4, grifo nosso).

Como argumentamos, com Vieira Pinto, isso é função humanizadora da técnica, ela atua como espelho para que o homem possa enxergar novas nuanças de sua própria existência. O sentido da implicação asseverada por Demo não parece indicar uma necessidade. Parece, muito mais, apontar para uma responsabilidade que se precisa assumir diante dos novos caminhos propiciados, o que não se tem observado largamente. Ao invés disso, incorre-se frequentemente em uma tecnocracia que, segundo Miriam Matos e Maria Zilah Albuquerque (2010), corresponde à subordinação do existir diário, nos seus diversos desdobramentos, aos processos produtivos, aos instrumentos e às técnicas, o que pode abranger a educação. Nesse cenário, a tecnologia parece avançar com muito mais velocidade do que a transformação da mentalidade.

Essa tecnocracia, ou o tecnicismo, se aproxima da definição de androide de Philip K. Dick (1995, p.191): “[...] permitir tornar-se um mero instrumento, ou ser forçado, ou manipulado, a se tornar um sem seu conhecimento ou consentimento". Mas, ele alerta: "[...] você não pode transformar um humano em um androide se esse humano for quebrar as leis a cada oportunidade. 'Androidização' requer obediência. E, mais que tudo, predicabilidade" (tradução nossa). Ora, uma educação realmente democrática, da autonomia e da cidadania pretende formar o oposto de autômatos.

A técnica pode auxiliar a humanização a ampliar a comunicação entre os homens, a realizar numerosos ideais que a educação nacional tem preconizado. Mas, para isso, ela precisa ser compreendida como o meio a serviço de uma conduta comprometida com esses ideais em diversos níveis. É precisamente aí que é necessário recorrer à epistemologia. A vigilância é dimensão sine qua non.

Deixada à conservação e à ingenuidade, a técnica opera como fato, como verdade fria e inquestionável. Sustenta, assim, a alienação do fato de que ela é parte de uma construção humana, que ela não encerra nenhum processo, mas permite enxergar novas possibilidades que permitem um avanço cada vez mais sofisticado. Mas a vigilância necessária depende de um compromisso real e vivo, de atitude, muito mais que de discurso. Não se implementa um processo tão difícil e oneroso sem que haja um real valor agregado à prática didática democrática.

Phillip K. Dick, sobre o avanço da tecnologia, afiançou que "[...] nosso voo não deve se apenas para as estrelas, mas para dentro da natureza de nosso próprio ser. [...] Ad astra, mas per hominum. E nunca devemos esquecer disso" (1995, p.189, tradução nossa). Sobre o filme, Vale (1999) argumenta 
que há uma conciliação entre o homem e a máquina ativada pelo gesto desta última. A técnica reflete para o homem sua própria humanidade.

\title{
Conclusão
}

Há quem diga que a epistemologia nada tem a ver com esse compromisso. Mas qualquer um pode estudar até onde vai a vigilância epistemológica. Até aquele nível que reencontra o devir humano. Como o próprio Bachelard garantiu:

\begin{abstract}
Quando se trata de estudar os homens, semelhantes, irmãos, a simpatia é a base do método. [... Mas] Os eixos da poesia e da ciência são princípios inversos. Tudo o que a filosofia pode esperar é tornar a poesia e a ciência complementares, uni-las como dois contrários bem feitos (BACHELARD, 1994, p.2, grifo nosso ).
\end{abstract}

O ser humano parte sempre de um certo deslumbramento estético, de uma insurgência primitiva das intuições capaz de aduzir o fenômeno novo, criativo. O deslumbramento inicial pode se expressar como uma fobia ou uma filia, isso é inevitável. No entanto, o espírito científico precisa partir dessas intuições ingênuas, mas atuar sobre elas destruindo-as, rompendo o obstáculo epistemológico que advém da nova visão (BACHELARD, 1994, p.8).

Batty recorda que se não tivessem sido usados de forma muito irresponsável e bitolada, no início, e, depois, combatidos e "aposentados"; caso a relação homem-máquina tivesse sido dialógica e conjunta, muito do mundo desconhecido poderia ter sido revelado. Novos fenômenos, frutos da técnica, poderiam advir e alimentar o espírito científico com a novidade do devir.

Eis a lição que podemos obter com a reflexão em torno da vigilância da técnica educacional. Se ela existe e foi produzida cientificamente, cabe a cada um operar a antipatia pela sua apropriação ingênua, pelo tecnicismo. Cada um precisa se rearticular com o sentido próprio da técnica, em seu valor científico seguro. Isso há de revelar novos horizontes da sociedade, da aprendizagem, das relações construídas no fazer educacional.

É aí que fincamos nosso marco de chegada de toda esta discussão: não se trata de uma defesa ou oposição à tecnologia educacional, o que é uma escolha de tipo sentimental. Trata-se, sim, de apontar como necessária (no sentido filosófico) a reflexão epistemológica para o seu uso ético e engajado. Somente assim, nos parece ao cabo da reflexão operada, é possível minorar a perda dessas novas visões no tempo, como lágrimas na chuva, e, assim, a tecnologia educacional pode ser auxiliar para a realização, a revelação e a emancipação do homem. 


\section{Referências}

BACHELARD, Gaston. O racionalismo aplicado. Rio de Janeiro: Zahar, 1977.

. Lautréamont. Lisboa: Ed. 70, 1989.

. A psicanálise do fogo. São Paulo: Martins Fontes, 1994.

. A formação do espírito científico: contribuição para uma psicanálise do conhecimento.

Rio de Janeiro: Contraponto, 1996.

.. A Epistemologia. Lisboa: Ed. 70, 2006.

. A poética do devaneio. São Paulo: Martins Fontes, 2009.

BANDEIRA, Alexandre. O conceito de tecnologia sob o olhar do filósofo Álvaro Vieira Pinto. Geografia: ensino \& pesquisa, Santa Maria v.15, n.1, p. 111-114, jan-abr. 2011.

BARBOSA, Elyana. Gaston Bachelard e o racionalismo aplicado. Cronos, Natal v. 4, n. 1/2, p. 33-37, jan-dez/2003.

BARRA, Daniela Couto Carvalho et al. Avaliação da tecnologia Wiki: ferramenta para acesso à informação sobre ventilação mecânica em Terapia Intensiva. Rev. bras. enferm., Brasília, v. 65, n. 3, jun. 2012 . Disponível em: $<$ http://www.scielo.br/scielo.php?script=sci_arttext\&pi$\mathrm{d}=$ S0034-71672012000300011\&lng=en\&nrm=iso $>$. Acesso em: 01 jun. 2014.

RIDLEY, Scott; DEELEY, Michael. BLADE Runner..[filme-video] Produção de Michel Deeley, direção de Scotte Ridley. Estado Unidos, Warner Bros Pictures, 1982. 1 DVD, 117min.color. son.

BOSNAK, Metin. The nocturnal future as alienated existence: Blade Runner. Journal of Economic and Social Research [S.1.], v.3, n.2, p.73-97, 2002.

CORONEL, Daniel Arruda; SILVA, José Maria da. O conceito de tecnologia, Álvaro Vieira Pinto. Economia e tecnologia, [S.1.], v.6, n.20, p. 181-186, jan-mar. 2010.

CRITELLI, Dulce. Martin Heidegger e a essência da técnica. Margem, São Paulo, n.16, p.8389, dez. 2002.

DE BRUYNE, Paul; HERMAN, Jacques; SCHOUTHEETE, Marc. Dinâmica da pesquisa em ciências sociais. Rio de Janeiro: Francisco Alves, 1991.

DEMO, Pedro. Tecnofilia e tecnofobia. Boletim técnico do Senac, Rio de Janeiro, v.35, n.1, jan-abr. 2009. $\overline{\text { nov. } 2010 .}$

"Novas tecnologias": novas? Diálogos educacionais, Campo Grande, v.1, n.1, p.1-18,

DICK, Philipe. K. Blade Runner: perigo iminente. (Do androids dream of electric sheep?). Lisboa: Europa-América, 1984. 
JESUINO, F. M.; LIMA, M.A. M.; SOUZA, A. M. C.; MARINHO, G. S. Lágrimas na chuva: reflexão...

. The android and the human (1972). In: SUTIN, Lawrence (Ed.) The shifting realities of Philip K. Dick: selected literary and philosophical writings. New York: Vintage Books, 1995.

FERREIRA FILHO; DUARTE, Valter. De Bachelard para as Ciências Sociais. In: BULCÃO, Marly (Org.). Bachelard: Razão e Imaginação. Feira de Santana: Universidade Federal de Feira de Santana, 2005, p. 333-347.

FONSECA, Luciana Mara Monti et al. Evaluation of an educational technology regarding clinical evaluation of preterm newborns. Rev. Latino-Am. Enfermagem, Ribeirão Preto, v. 21, n. 1, fev. 2013. Disponível em: $<$ http://www.scielo.br/scielo.php?script=sci_arttext\&pi-

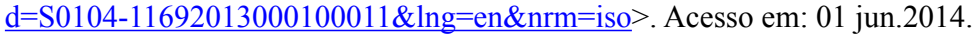

FROTA, Natasha Marques et al . Construção de uma tecnologia educacional para o ensino de enfermagem sobre punção venosa periférica. Rev. Gaúcha Enfermagem, Porto Alegre, v.

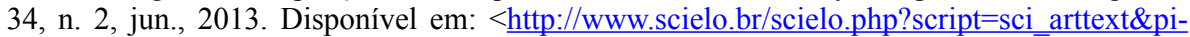
$\mathrm{d}=\mathrm{S} 1983-14472013000200004 \& \operatorname{lng}=\mathrm{en} \& \mathrm{nrm}=\mathrm{iso}>$. Acesso em: 01 jun.2014.

HEIDEGGER, Martin. A questão da técnica. In: HEIDEGGER, M. Ensaios e conferências. Petrópolis: Vozes, 2008.

JESUINO, Filipe M.; JESUINO, Sabrina Leite Cardoso dos Santos; RIOS, Clauberson Sales do Nascimento. Para além da imagem: os impactos subjetivos provocados pelas novas tecnologias de imageamento. In: SANTANA, J.R.; FIALHO, L.M.F.; SANTOS-JR; F.F.U.; SENA, M.A. (Orgs.). Bioinformática, Ciências Biomédicas e Educação. Fortaleza: Edições UFC, 2011.

LIMA, Marcos Antonio Martins. Um novo projeto epistemológico e teórico para a avaliação educacional: uma aplicação da autoavaliação em instituições de ensino superior do setor privado. 2004. 533 fls. Tese [Doutorado em Educação]. Faculdade de Educação/Programa de PósGraduação em Educação Brasileira, Universidade Federal do Ceará, Fortaleza, 2004.

MATOS, Miriam Gondim; ALBUQUERQUE, Maria Zilar Sales de. Técnicas de avaliação educacional de ensino-aprendizagem: um estudo de caso em uma instituição de ensino superior instalada na cidade de Fortaleza (CE). In: LIMA, Marcos Antonio Martins; MARINELLI, Marcos. Epistemologias e metodologias para avaliação educacional: múltiplas visões e abordagens. Fortaleza: Edições UFC, 2010.

NESPOLI, Grasiele. Os domínios da Tecnologia Educacional no campo da Saúde. Interface, Botucatu, v. 17, n. 47, dez. 2013. Disponível em: < http://www.scielo.br/scielo.php?pi$\mathrm{d}=\mathrm{S} 1414-32832013000400009 \&$ script $=$ sci abstract\&tlng=pt $>$. Acesso em: 01 jun.2014.

SIMÕES, Viviane Augusta. Utilização das tecnologias educacionais nas escolas da rede estadual da cidade de Umuaruma - PR. 2002, 119f. Dissertação [Mestrado em Educação]. Programa de Mestrado em Educação. Universidade Federal de Uberlândia, Uberlândia, 2002.

VALE, Mario. Blade Runner: o nosso futuro comum? Inforgeo, Lisboa, n. 14, p. 197-200, 1999.

Submissão em: 15/09/2013

Revisão em: 01/04/2014

Aceite em 01/04/2014 
Filipe de Menezes Jesuino é Mestre em Psicologia e doutorando em Educação pela Universidade Federal do Ceará, Brasil (2008). Endereço para correspondência: Rua Araújo Torreão, 64. Parque Iracema, CEP 60824-190, Fortaleza/CE. E-mail: filipemjesuino@gmail.com

Marcos Antonio Martins Lima é Doutor em Educação pela Universidade Federal do Ceará, Brasil (2004). Professor Adjunto da Universidade Federal do Ceará, Departamento de Fundamentos da Educação/FACED. E-mail: $\underline{\text { marcos.a.lima@terra.com.br }}$

Andréa Moura da Costa Souza é Mestre em Sciences et Gestion pela Universite Nancy 2, França (2006) e doutoranda em Educação pela Universidade Federal do Ceará. E-mail: andreamoura.ufc@gmail.com

Gabrielle Silva Marinho é Mestre em Educação pela Universidade Federal do Ceará, Brasil (2012) e doutoranda em Educação da Universidade Federal do Ceará, Brasil. E-mail: gabrielle_marinho@hotmail.com 